\title{
Gerência de Projetos: utilizando conceitos de Bolsa de Valores no ensino
}

\author{
Rogério Güths ${ }^{1}$, Gerson Antunes Soares ${ }^{2}$, Bárbara Barros ${ }^{1}$, Anderson Guirardi ${ }^{1}$ \\ ${ }^{1}$ Curso de Sistemas de Informação - Universidade Federal do Mato Grosso do Sul \\ (UFMS) - Caixa Postal 252 - 79.304-902 - Corumbá - MS - Brasil \\ ${ }^{2}$ Curso de Sistemas de Informação - Universidade Luterana do Brasil (ULBRA) \\ BR 285 Km 335 - 99.500-000 - Carazinho - RS - Brasil \\ \{rguths, gersonsoares\}egmail.com, \\ \{brgbarros, andersonguirardi\} @yahoo.com.br
}

\begin{abstract}
This article describes the application of Stock Market's concept to help the Project Management teaching. It covers Stock Market and Project Management fundamental concepts and presents experiences in the application of these concepts in the Project Management discipline that is a part of an Information System course in a Brazilian university. These experiences starts with the project planning followed by the execution of a stock exchange, where students could invest on projects and ran the risk of making bad investments.
\end{abstract}

Resumo. O presente artigo descreve a aplicação de conceitos de Mercado de Ações no auxílio ao ensino de Gerência de Projetos. São abordados conceitos fundamentais de Mercado de Ações e Gerência de Projetos. São relatadas experiências de aplicação destes conceitos na disciplina de Gerência de Projetos no curso de Bacharelado em Sistemas de Informação de uma universidade brasileira através de uma atividade de elaboração de projeto seguida pela execução da bolsa de projetos, no qual os alunos investiam nos projetos estando sujeitos ao risco de realizarem maus investimentos.

\section{Introdução}

Um projeto é um empreendimento não repetitivo, caracterizado por uma sequência clara e lógica de eventos com início, meio e fim, que se destina a atingir um objetivo claro e definido, sendo conduzido por pessoas dentro de parâmetros pré-definidos de tempo, custo, recursos envolvidos e qualidade. De forma mais sucinta o Project Management Institute em PMI (2002) define projeto como "um empreendimento temporário com o objetivo de criar um produto ou serviço único".

O estudo de Gerência de Projetos é parte importante no currículo de cursos de Bacharelado em Sistemas de Informação, normalmente sob a forma de uma disciplina, mas também como parte de outra disciplina atrelada a área de Sistemas de Informação ou Engenharia de Software. Juntamente com disciplinas de Sistemas de Informação, 
Introdução à Administração, Empreendedorismo e outras compõem uma importante parcela no perfil do egresso destes cursos relacionada à gestão e liderança de equipes.

Estuda-se Gerência de Projetos para se ter maior possibilidade de sucesso nos projetos. O ensino é caracterizado pelo uso intensivo de exemplos práticos, que permitem ao acadêmico enriquecer sua percepção da área e seus problemas, mesmo que não tenha experiência profissional em Gerência de Projetos. Conforme o PMI (2002) quanto mais se usa a metodologia, aumentam a maturidade e a chance de sucesso nos próximos projetos.

O ambiente acadêmico não é propício a atividades de Gerência de Projetos, devido a limitações de tempo e recursos disponíveis. O desafio ao professor é propiciar experiências ricas, apesar destas restrições.

Neste contexto, o presente artigo apresenta uma atividade que foi realizada com bons resultados em turmas da disciplina de Gerência de Projetos e propõe a execução desta em cursos da área. Os dois objetivos principais desta atividade são:

- Incrementar a experiência dos alunos na elaboração e apresentação de projetos.

- Aguçar a análise e julgamento de projetos.

O artigo está organizado da seguinte maneira, primeiro são feitas considerações sobre Gerência de Projetos. Em seguida, é detalhada a fase de planejamento. Na próxima seção são relatados conceitos básicos do Mercado de Ações. Posteriormente, é mostrada a aplicação dos conceitos abordados nas seções anteriores em experiências para três turmas da disciplina de Gerência de Projetos, em curso de Bacharelado em Sistemas de Informação. Por último são apresentados os resultados alcançados e algumas sugestões na forma de desenvolver esta atividade.

\section{Gerência de Projetos}

Desde os anos 60 vem sendo estudada Gerência de Projetos. O PMI é o pioneiro na regulamentação e distribuição deste conhecimento. O PMI é uma entidade internacional sem fins lucrativos que congrega os profissionais de áreas relacionadas à Gerência de Projetos (Project Management). Fundado em 1969 nos EUA, atualmente está presente praticamente no mundo inteiro. Sua missão é promover o profissionalismo e o "estadoda-arte" na gestão de projetos provendo aos seus associados serviços e produtos e estabelecendo a aceitação do gerenciamento de projetos como uma disciplina e uma profissão.

O PMI em PMI (2002) reuniu a teoria de gestão em um documento chamado Project Management Body Of Knowledge (PMBOK). O PMBOK contém orientações para os profissionais sobre o conhecimento em gerenciamento de projetos. É um guia de referência, mas não explicita em detalhes a implementação dos processos sugeridos.

O PMI classifica os processos necessários ao sucesso de um projeto em nove áreas, chamadas áreas do conhecimento: escopo, custo, prazo, qualidade, recursos humanos, comunicação, riscos, aquisições (ou terceirizações) e integração. Cada uma destas áreas deve ser conhecida, entendida e praticada pelo gerente de projetos para que 
seu projeto tenha êxito. Por outro lado, os processos de Gerência de Projetos podem ser organizados em cinco grupos obedecendo uma ordem cronológica, cada um deles contendo um ou mais processos:

- Iniciação - processo de organização inicial e autorização do projeto.

- Planejamento - processo no qual ocorre a definição e refinamento dos objetivos e seleção da melhor das alternativas de ação.

- Execução - processo em que pessoas e outros recursos são coordenados para realizar o planejamento proposto.

- Controle - processo que assegura que os objetivos do projeto estão sendo atingidos, através da monitoração regular identificando variações do planejamento e demandando ações corretivas quando necessário.

- Encerramento - processo que formaliza a aceitação do projeto e encerramento de uma forma organizada.

Conforme Martins (2007), as áreas estão sujeitas às interações até o fím do projeto. Por exemplo, se a data prevista para o término for antecipada, a qualidade, o custo, ou o escopo podem necessitar de alteração. Além disto, planejamento não é uma ciência exata - equipes distintas podem gerar planos diferentes para o mesmo projeto.

\section{Planejamento}

Dentre os grupos, cabe destacar o de planejamento, que é de fundamental importância num projeto, porque executar um projeto implica em realizar algo que não tenha sido feito antes. Como conseqüência, existe relativamente mais processos nessa seção. A quantidade de planejamento elaborada deve estar de acordo com o escopo do projeto e com a utilidade da informação desenvolvida. Planejar é um esforço contínuo durante toda a vida do projeto.

Até o momento da iniciação, o projeto não iniciou oficialmente. O início se dá com a aprovação de documentos em que todos os interessados, de comum acordo, estabelecem as linhas gerais do projeto.

A primeira tarefa do gerente de projeto é desenvolver o planejamento convertendo as metas e informações documentadas na iniciação em um plano de ação que permita a todos os interessados compreender (e executar) claramente o trabalho a ser realizado.

Na fase de planejamento: a equipe é montada; o escopo do produto é detalhado; o escopo do projeto é definido; o prazo e custo são estimados; os riscos são identificados e avaliados, sendo planejadas ações preventivas para os mais perigosos; as formas de comunicação são estabelecidas. Nesta fase todas as áreas do conhecimento são afetadas.

A base para todo este planejamento é a definição do escopo do produto, indicando o que vai ser entregue ao cliente.

O principal objetivo das atividades é a elaboração do Plano do Projeto, que contém as seguintes informações: 
- Escopo detalhado do Projeto (WBS - Work Breakdown Structure),

- Cronograma detalhado do projeto (com previsões de datas de término cedo e tarde e Análise do Caminho Crítico),

- Análise de Custos e Fluxo de Caixa,

- Planejamento de Recursos Humanos e Recursos Materiais,

- Planejamento da Gerência de Riscos,

- Planejamento de Comunicação.

Além das atividades relacionadas à elaboração do Plano de Projeto, existem atividades que visam a definição das terceirizações, dos requisitos de qualidade e da forma de monitoração.

Se todos estes fatores forem bem planejados e executados, teremos um projeto de qualidade. Desta forma, a preparação de bons gerentes de projeto demanda ênfase no planejamento, uma vez que a execução de um projeto de software é difícil no contexto de disciplinas regulares de graduação.

De forma simplificada pode-se dizer que a fase de planejamento visa responder a pergunta: quem estará fazendo o que em determinado momento?

\section{Mercado de Ações - Capitais}

De acordo com BOVESPA (2011) o mercado de capitais é um sistema de distribuição de valores mobiliários, que tem o propósito de proporcionar liquidez aos títulos de emissão de empresas e viabilizar seu processo de capitalização. Os principais títulos negociados são os representativos do capital de empresas - as ações — que permitem a circulação de capital para custear o desenvolvimento econômico das empresas em questão. Ações são títulos de renda variável, emitidos por sociedades anônimas, que representam a menor fração do capital da empresa emitente. Podem ser escriturais ou representadas por cautelas ou certificados. $\mathrm{O}$ investidor em ações é um co-proprietário da sociedade anônima da qual é acionista, participando dos seus resultados. As ações são conversíveis em dinheiro, a qualquer tempo, pela negociação em bolsas de valores ou no mercado de balcão.

Desta forma, os investidores buscam a melhor relação entre três aspectos básicos de um investimento: retorno, prazo e proteção. No momento de escolher a ação a investir, é preciso analisar a provável rentabilidade, liquidez e grau de risco. Na maioria das vezes, a rentabilidade é diretamente proporcional ao risco. A liquidez, no caso de ações, é imediata. É através da venda de ações que as empresas obtêm recursos para seu crescimento e estes investimentos proporcionam crescimento econômico e este, por sua vez, gera aumento de renda. É pela participação de novos acionistas que uma empresa ganha condição de obter novos recursos, em contrapartida estes passam a ser sócios da empresa.

De certa forma, o investidor em ações viabiliza a criação de novos produtos ou a melhoria de processos de produção. Como acionista, ele é sócio da empresa e se beneficia da distribuição de dividendos sempre que esta obtiver lucros. Assim, o investidor ao tornar-se acionista da empresa está apostando no sucesso desta ao invés de 
outra. Se por um lado recebe dividendos caso a empresa obtiver lucros, por outro lado perde valor a ação se esta obtiver prejuízo, de forma que, se quiser comercializar a ação para outro, esta terá valor inferior àquele pago anteriormente. Portanto, investimento acertado rende e investimento errado causa prejuízo.

Nos investimentos em mercados de capitais estão bem presentes dois aspectos fundamentais à área de Gerência de Projetos: os riscos e a viabilidade. Se uma empresa não for viável a médio e longo prazo, as ações desta perderão valor. Do mesmo modo, um projeto que não foi bem planejado não é viável, considerando as restrições de tempo, custos, escopo ou qualidade impostos ao projeto. Consequentemente não será bem sucedido. Por outro lado, tanto no contexto de empresas como no de projetos, existem eventos inesperados que podem prejudicá-los. A ocorrência destes riscos pode fazer o valor das ações diminuir.

\section{Bolsa de Projetos e sua Execução}

O ensino de Gerência de Projetos é caracterizado pelo uso intensivo de exemplos práticos (cases). O uso de exemplos práticos busca enriquecer, no acadêmico, a percepção da área e seus problemas, mesmo que não tenha experiência profissional no tema.

Cabe ao professor propiciar experiências em sala de aula que remetam o mais próximo possível da realidade do tema.

Visando a formação completa do aluno em Gerência de Projetos devemos levar em conta que:

- Segundo Shenhar, Raz e Dvir (2003), o planejamento é fundamental para o sucesso de um projeto, portanto deve ser uma das áreas mais exigidas.

- A experiência completa de Gerência de Projetos envolve todas as fases de um projeto, em especial as de planejamento e execução.

- Determinados projetos de softwares podem demandar mais de um ano na sua execução. Desta forma, no âmbito de uma disciplina, fica inviável propiciar a cada aluno a experiência completa de ser gerente de um projeto na área de desenvolvimento, devido a restrições de recursos humanos e financeiros.

- Análise de risco é uma das essências de Gerência de Projetos, mas em trabalhos acadêmicos tradicionais não existem maiores riscos envolvidos, com exceção de uma nota baixa a qual não está diretamente relacionada à sensação de perda ou insucesso.

- De acordo com Dinsmore e Cavalieri (2003) riscos são muito importantes para o sucesso do projeto, e estão associados a ganhos ou perdas.

-Utilizando-se da análise de diversos planejamentos o acadêmico aguça a capacidade crítica e de distinção entre um projeto bom e um mau.

Desta forma, planejou-se a seguinte estratégia de ensino:

- Os acadêmicos foram os responsáveis pela escolha dos temas, coleta de informações, elaboração e apresentação do projeto. Os temas deveriam estar restritos ao desenvolvimento de software com perspectivas de comercialização imediata. 
- Cada projeto deveria conter: viabilidade, descrição do produto a ser desenvolvido, recursos necessários (financeiros, prazos e humanos) e planejamento conforme a metodologia proposta pelo PMI (2002).

- Na data de apresentação dos projetos, cada acadêmico foi convidado a investir recursos de $\mathrm{R} \$ 5,00$, que eram convertidos em papéis, porém os alunos que não desejassem participar por quaisquer motivos tinham liberdade para tal.

- Ao final das apresentações, cada acadêmico deveria escrever no verso de seus papéis seu nome e o projeto no qual aquele papel estava sendo investido.

- Na entrega dos seus papéis, cada aluno justificava seu investimento.

- O acadêmico não podia investir em seu próprio projeto.

- Os três projetos que mais recebessem investimentos teriam seu valor convertido em reais através dos papéis.

- Os papéis investidos nos demais projetos perdiam o valor, que era convertido em um lanche na próxima aula dividido para todos.

- O professor apresentava uma análise crítica sobre os projetos constando: seu parecer sobre os projetos indicando os melhores na sua avaliação, a correlação entre esta e os projetos vencedores, uma analise das justificativas dos investimentos e sugestões de melhoria, em cada projeto.

- Para finalizar a atividade, realizava-se debate sobre a atividade, as avaliações e sugestões de melhoria.

A figura 1 resume as etapas da estratégia de ensino.

1) Alunos trocam $R \$$ pelo direito a investir
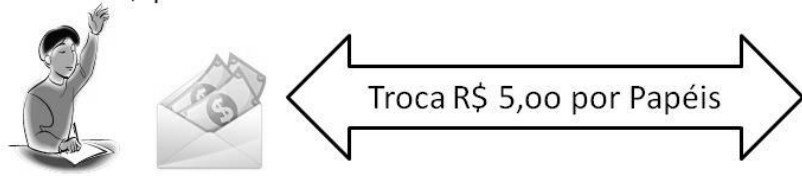

2) Todos os projetos são apresentados
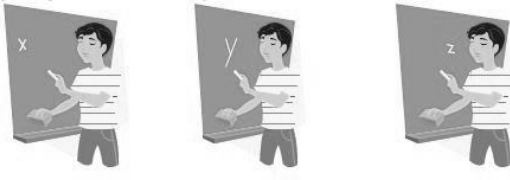

3) Investimentos são realizados e argumentados
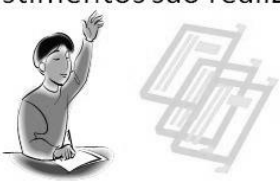

Investe e Argumenta

4) Os 3 projetos mais investidos retornam seu investimento

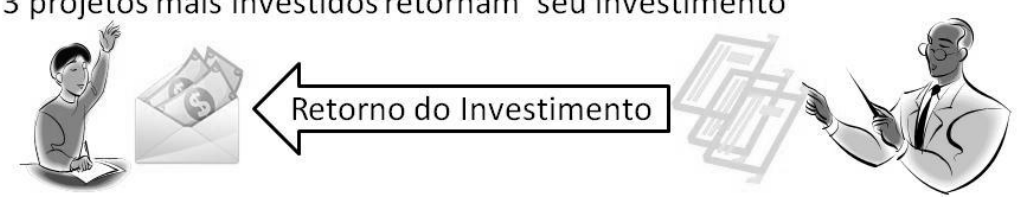

Figura 1. Resumo das etapas da estratégia de ensino, relativas a apresentação

A avaliação do professor analisou as seguintes questões: 
- O escopo está bem definido?

- Foi comprovada viabilidade financeira?

- Definiu corretamente cronograma, atribuição de responsabilidades e marcos de projeto?

- Comprovou a exequibilidade do cronograma?

- Previu adequadamente os recursos humanos necessários?

- Está prevista comunicação interna e externa do projeto?

- Nos marcos de projeto estão previstos critérios de qualidade para aprovação?

- Os riscos previstos e trabalhados são coerentes com o projeto?

Nem todos os projetos vencedores em investimentos foram os melhores na avaliação do professor, o que propiciou amplo debate sobre os pontos analisados, bem como sobre as justificativas para o investimento.

A tabela 1 resume as informações sobre as três execuções desta estratégia.

Tabela 1. Resumo das execuções da estratégia nas turmas

\begin{tabular}{|c|c|c|c|}
\hline Turmas & $\begin{array}{c}\text { Qtd de } \\
\text { alunos }\end{array}$ & $\begin{array}{c}\text { Qtd de } \\
\text { grupos }\end{array}$ & $\begin{array}{c}\text { Comparação entre as avaliações dos alunos e do } \\
\text { professor }\end{array}$ \\
\hline $2008 / 1$ & 14 & 6 & $\begin{array}{c}\text { Dos 3 projetos vencedores na avaliação dos alunos, } \\
\text { somente 1 o professor não considerou vencedor }\end{array}$ \\
\hline $2008 / 2$ & 19 & 9 & $\begin{array}{l}\text { Os 3 projetos vencedores na avaliação dos alunos } \\
\text { também foram os melhores avaliados pelo professor }\end{array}$ \\
\hline $2009 / 1$ & 13 & 6 & $\begin{array}{c}\text { Dos 3 projetos vencedores na avaliação dos alunos, } \\
\text { somente 1 o professor não considerou vencedor }\end{array}$ \\
\hline
\end{tabular}

Uma alternativa à devolução dos investimentos seria conferir lucros baseados nos investimentos perdidos, de forma a não sobrarem valores. Para não frustrar os perdedores, esta abordagem não foi utilizada.

\section{Conclusões}

Antes de analisar os resultados é importante frisar que o desenvolvimento dos conteúdos da disciplina é que fornece o embasamento para a elaboração do planejamento dos projetos. Este embasamento não muda com a aplicação ou não desta metodologia, portanto a metodologia em si não é responsável pela correta instrução ao acadêmico de como confeccionar um bom Plano de Projeto.

A metodologia utilizada, em que os alunos vivenciavam um ambiente real de Gerência de Projetos mostrou-se muito eficiente, tanto na motivação e comprometimento demonstrados pelos alunos quanto em seu desempenho na disciplina, corroborado através das avaliações finais. Porém, destaca-se que a melhora no desempenho de análise dos alunos depende muito do perfil da turma e da variação na qualidade dos projetos apresentados. Uma turma na qual os projetos são todos muito bons ou todos muito ruins terá menor amadurecimento neste aspecto. Particularmente na 
turma de 2008/2 ocorreu maior discrepância na qualidade dos projetos apresentados e, consequentemente o debate que finalizou a atividade foi o mais extenso de todos.

Nas turmas anteriores a de 2008/1 não era utilizada esta metodologia. Era solicitado um trabalho de planejamento de projeto idêntico ao descrito neste trabalho. A única mudança é que não acontecia a atividade de Bolsa de Projetos. No entanto, as diferenças foram grandes:

- Os acadêmicos, em sua grande maioria, ficavam dispersos enquanto ocorria a apresentação e defesa dos outros trabalhos.

- Os únicos questionamentos eram feitos pelo professor.

- Ao serem questionados sobre a qualidade dos demais projetos os acadêmicos, diplomaticamente, afirmavam que todos eram de boa qualidade.

- Não existia a noção de risco, que é muito importante na área de Gerência de Projetos.

- Ao apresentar a viabilidade, os grupos não se preocupavam em tentar convencer os ouvintes da qualidade de seu projeto e também não se preocupavam se o mesmo era, de fato, viável.

- Como a grande maioria dos acadêmicos apenas se preocupava com a sua própria apresentação, a análise crítica e o questionamento final ficavam esvaziados e restritos às ponderações do professor.

- Pouco ou nada era exercitado em relação à avaliação ou classificação de projetos. Não havia incentivo aos acadêmicos para que identificassem bons ou maus projetos.

- Como não era exercitada a avaliação, os acadêmicos também não refletiam sobre as características mais importantes e necessárias a um bom projeto.

Para que a atividade seja bem sucedida, sugerem-se algumas limitações:

- Número máximo de oito grupos.

- Apresentações entre quinze a vinte minutos por grupo, com até cinco minutos para questionamentos.

- Idealmente a atividade deve ter início e término na mesma aula, alocando três a quatro horas, porém, se não for possível, os acadêmicos devem compor "checklist" de avaliação para os projetos, anotando as principais características observadas em cada um.

Este tipo de atividade é altamente recomendado para turmas de Gerência de Projetos, pois propicia importante prática no planejamento e análise de projeto. A atividade é propícia a disciplinas que exijam análise crítica, julgamento ou classificação. Acredita-se que esta atividade possa ser estendida a qualquer outra disciplina que envolva alguma das seguintes idéias: planejamento de produto ou serviço; venda de produto; convencimento do público ou clientes por parte dos proponentes.

\section{Referências}

BOVESPA (2011) Mercado de Capitais. Disponível em: http://www.bmfbovespa.com.br/Pdf/merccap.pdf Acesso em 20 de Janeiro de 2011. 
PMI (2002) Tradução livre do PMBOK 2000 Disponível em: http://www.mp.ap.gov.br/tecnologia/wp-content/uploads/2010/03/608_PMBOK2000Portugues.pdf . Acesso em 15 de setembro de 2010.

Dinsmore, P., C., Cavalieri, A. (2003) Como se Tornar um Profissional em Gerenciamento de Projetos, Editora Qualitymark, SP, 2003.

Shenhar, A., Raz, T. e Dvir, D. (2003) An Empirical Analysis of the Relationship Between Project Planning and Project Success. International Journal of Project management, 21, $2: 89-95$, (2003)

Martins, J.C. (2007) Gerenciando projetos de desenvolvimento de software com PMI, RUP eUML. $4^{\text {a }}$ ed. Brasport, Rio de Janeiro, 2007.323p 